\title{
AQUISIÇÃO DE DADOS ESPACIAIS E ANÁLISE DA QUALIDADE DE PRODUTOS CARTOGRÁFICOS OBTIDOS ATRAVÉS DE RPA
}

\author{
SPATIAL DATA ACQUISITION AND QUALITY ANALYSIS OF CARTOGRAPHIC PRODUCTS \\ OBTAINED THROUGH RPA
}

\author{
Mariana Sarah Suica TORRES; Rhassanno Caracciolo PATRIOTA \\ Programa de Pós-Graduação em Ciências Geofísicas e Tecnologias de Informação. Universidade Federal de Pernambuco. UFPE. \\ Avenida da Arquitetura, s/n. Recife - PE. E-mails: suicamariana@gmail.com; rhassanno@gmail.com

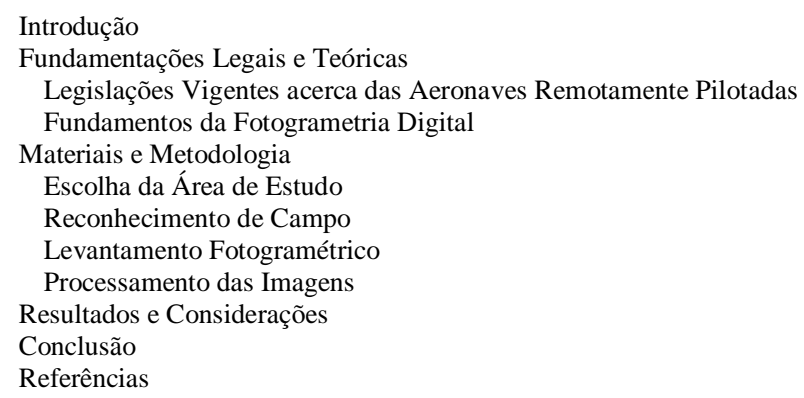

RESUMO - Com o aumento recente da utilização de Aeronaves Remotamente Pilotadas (RPAs), aeronaves remotamente pilotadas, para diversas finalidades, surge, além da preocupação referente à legislação específica, questionamentos relacionados à acurácia dos produtos gerados e sua classificação perante o Padrão de Qualidade Posicional (PEC). Com o intuito de produzir e avaliar os dados cartográficos e produtos fotogramétricos obtidos utilizando esta tecnologia e propondo uma abordagem de baixo custo, foi escolhida uma porção do Riacho Cavouco, afluente do rio Capibaribe situado dentro da Universidade Federal de Pernambuco, como a área de estudo e de levantamento de voo. Neste estudo, mostrou-se que RPAs possibilitam a diversificação de produtos fotogramétricos com alta acurácia, atendendo a classe A da PEC.

Palavras-Chave: Fotogrametria, RPA, Dados Espaciais.

\begin{abstract}
With the recent enlargement of utilization of Remotely Piloted Aircraft (RPAs), remotely piloted aircraft to various purposes, a concern comes up, not only about the specific legislation but also about questionings related to the accuracy of the created products and their classification according to the pattern of positional quality (PEC). With the intent of producing and evaluating the cartographic data and photogrammetric products obtained through this technology and proposing a low cost approach, a portion of the Cavouco stream, affluent of the Capibaribe River located inside the Federal University of Pernambuco as the study area and the RPA takeoff. In the study, it was shown that RPAs can provide a wild range of photogrammetric products with high accurary, fitting on the A class of the PEC.
\end{abstract}

Keywords: Photogrammetry, RPA, Spatial Data.

\section{INTRODUÇÃO}

$\mathrm{O}$ recente e rápido crescimento de processamento e de capacidade de memória dos computadores tem tornado a aquisição e o manuseio das imagens digitais 3D tecnicamente mais acessíveis, mesmo em computadores pessoais compactos, tornando os modelos 3D utilizáveis em uma vasta gama de campos científicos, tais como a medicina, a indústria de filmes, a engenharia, arquitetura e geologia (Yilmaz et al., 2018). Entrou em foco a fotogrametria digital, que tem se apresentado como uma válida alternativa devido ao grau de acurácia que proporciona e pelo baixo custo financeiro (Kangas et al., 2018), o que viabilizou o seu uso em métodos para obtenção de dados espaciais (Unhammer, 2016).

Com esse avanço tecnológico, desde 2010, intensificou-se o processo de aquisição de dados espaciais através de RPAs, expandindo o potencial de mapeamento de áreas que estava limitada a satélites para pequenas escalas e a fotogrametria aérea utilizando aviões, que possuíam como desvantagem o alto custo, as baixas resoluções temporal e espacial (Harwin \& Lucieer, 2012, 2013; Skarlatos et al., 2013). Se de um lado as RPAs seguem ganhando espaço sendo alternativa para o uso as imagens orbitais, aerolevantamentos com aviões e até mesmo, métodos topográficos, com baixo custo e alta resolução espacial e temporal, de outro lado, por razões de segurança, surgiram questionamentos legais relacionado à aviação civil, o que fez essencial a regulamentação do acesso das RPAs ao espaço, dividem o espaço aéreo com outras 
tecnologias plenamente regulamentadas.

Nesse contexto, tendo em vista as possibilidades de aquisição de dados especiais a partir de aerolevantamento usando RPAs, cujas nuvens de pontos 3D resultante possuem qualidade similar a nuvens de pontos obtidas por sistema de perfilhamento a laser (Harwin \& Lucieer, 2012), entrou em pauta o desenvolvimento de metodologias que atendam aos requisitos legais, a partir da criação e alteração de legislações específicas, e técnicos, referente à acurácia e precisão adequadas aos produtos desejados após o processamento de dados, além do questionamento em relação à aplicabilidade dos produtos obtidos por RPAs em diferentes esferas científicas, incluindo a ambiental.

Considerando a possibilidade de obtenção de dados espaciais utilizando aeronave remotamente pilotada, o objetivo do experimento foi obter dados espaciais da área em questão utilizando uma RPA, a fim de realizar o levantamento e obter produtos fotogramétricos utilizando apoio de receptor GNSS, softwares de processamento fotogramétrico e desenho assistido por computador (CAD).

\section{FUNDAMENTAÇÕES LEGAIS E TEÓRICAS}

\section{Legislação Vigente Acerca das Aeronaves Remotamente Pilotadas}

Nos últimos anos, com o avanço da tecnologia e consequente redução de preços, as aeronaves remotamente pilotadas (RPA) tornaram-se efetivas usuárias do espaço aéreo, com os mais variados tipos de aplicação, desde à recreação ao uso em combate militar. O aumento do uso de RPAs em aplicações civis tem apresentado desafios a inúmeros países no que se refere a regulação e o emprego desses equipamentos, tanto no aspecto relacionado à privacidade quanto à segurança pública e nacional (Levush, 2016).

Em 2006, a Organização de Aviação Civil Internacional (OACI) é o responsável pela padronização de conceitos, dos princípios e termos reguladores do uso civil de aeronaves remotamente pilotadas, mas as nomenclaturas adotadas pela OACI ainda não são utilizadas em todos os países, implicando numa diferenciação de terminologia (Stoker et al., 2017).

Segundo (Bennett et al., 2017), com o objetivo de dar segurança a todos os usuários do espaço aéreo, os países que regulamentaram o uso de RPAs abordaram principalmente três aspectos: o acesso ao espaço aéreo, limitações operacionais e procedimentos administrativos de permissões de voo, licenças de piloto e autorização de coleta de dados

No Brasil, a Agência Nacional de Telecomunicações (Anatel), a Agência Nacional da Aviação Civil (Anac), o Departamento de Controle do Espaço Aéreo (Decea) e o Ministério da Defesa são os órgãos competentes para regulamentar o uso de RPAs.

A Anac, ao aprovar o RBAC-n ${ }^{\circ}$ 94, em 02 de maio de 2017, estabeleceu os requisitos gerais para o uso civil de aeronaves não tripuladas, abordando matéria exclusivamente técnica sobre a segurança da aviação civil, definindo nomenclaturas, responsabilidades, classes de aeronaves, requisitos para obtenção de certificado de aeronavegabilidade, regras de voo e para aprovação de projetos de RPA.

Por seu turno, o DECEA, através da ICA 10040, fazendo uso de sua competência legal, estabeleceu normas acerca dos procedimentos para o acesso ao espaço aéreo por sistemas de aeronaves remotamente pilotadas (RPAS), tanto para usuários de uma forma geral, quanto para órgãos públicos específicos, contemplados na AIC 23/2017 e na AIC 24/2018 (BRASIL, 2017; BRASIL, 2018).

Portanto, no Brasil, para utilizar RPAs de forma recreativa ou não é necessário atender as normas desses órgãos no que diz respeito à qualidade do enlace de rádio, características das técnicas da aeronave, regras de voo, avaliação de riscos operacionais e a forma de ingresso no espaço aéreo brasileiro.

No ano de 1984 , o decreto de $n^{\circ} 89.817$ passou a estabelecer as normas técnicas previstas as entidades públicas e privadas, produtoras e usuárias de serviços cartográficos, com a finalidade de estabelecer procedimentos e padrões a serem seguidos na elaboração e apresentação de normas da cartografia nacional (BRASIL, 1984). O avanço da tecnologia diminuiu a necessidade pela confecção manual e mecânica de produtos cartográficos, trazendo novas possibilidades, aplicações e novos métodos de manuseio. A distribuição de produtos feita por meio analógico permaneceu por considerável período de tempo e visava atender as necessidades dos usuários através de representações pictóricas. Com o avanço do geoprocessamento, desenvolvimento de SIG's e softwares de processamento de dados espaciais, 
surgiu a necessidade de buscar uma definição referente ao modo de aquisição da geometria dos dados espaciais e dos atributos correlatos, com o intuito de garantir a homogeneização da produção dos dados geoespaciais em território nacional (Exército Brasileiro, 2011). Surge, então, o PEC, padrão de exatidão cartográfica, indicador de qualidade que distingue as cartas a partir da classificação obtida (A,B, C, D).

\section{Fundamentos da Fotogrametria Digital}

A fotogrametria é a ciência de obtenção de geometria de três dimensões a partir de imagens, baseada nos princípios de trigonometria, utilizando fotografias sobrepostas tiradas de dois pontos diferentes (Chodoronek, 2015). Considerando o estudo morfológico do vocábulo "fotogrametria", que deriva da composição por aglutinação das palavras gregas photos, gramma e metron (luz, descrição e medidas, respectivamente), pode ser tomada como a técnica de "obter informação confiável dos objetos físicos e do meio ambiente, mediante processos de registro, medição e interpretação de fotografias e de modelos de energia radiante eletromagnética e outros fenômenos", de acordo com Slama (1980 segundo Rezende, 2016, p. 75).

Para Brito \& Coelho Filho (2007), a fotogrametria tem como objetivo a reconstrução de um espaço tridimensional denominado espaçoobjeto, a partir de um conjunto não vazio de imagens bidimensionais, chamado de espaçoimagem. Qualquer objeto tridimensional que possibilite o seu imageamento a partir de sensores que podem estar associados a qualquer plataforma é chamado de espaço objeto, ponto chave que define a classificação da fotogrametria em aérea, terrestre ou orbital.

Com o objetivo de reconstruir automaticamente o espaço-objeto a partir do espaço-imagem digital, o estado da arte está associado a metodologias que usam diversas rotinas automáticas para a confecção de produtos fotogramétricos, conexas a procedimentos supervisionados por operador (Brito \& Coelho Filho, 2007).

Desta forma, é possível realizar a transformação do espaço-objeto, por meio de imagens bidimensionais (espaço-objeto digital), independentemente da plataforma usada para transportar o sensor utilizado no imageamento, em representação tridimensional, através de técnicas fotogramétricas digitais semiautomáticas, que a cada dia exigem menos intervenção do operador.
Para atingir esse objetivo, da mesma maneira que a fotogrametria analógica, a fotogrametria digital requer planejamento prévio, contemplando a resolução espacial que se deseja obter para que, a partir das características do sensor de imageamento, seja possível definir a melhor distância em que a câmera se manterá do espaço-objeto e o espaçamento entre linhas e colunas da matriz de locação da câmera na seção de tomada fotográfica.

Para tanto, o conhecimento referente aos parâmetros de orientação interior e exterior da câmera são essenciais para o processamento fotogramétrico digital. Os parâmetros de orientação interior possibilitam a reconstrução do feixe perspectivo das imagens e a posterior ortorretificação (Brito \& Coelho Filho, 2007). A orientação interior consiste na recuperação da posição da fotografia em relação à câmera, reconstruindo o feixe perspectivo que gerou as fotografias (Andrade, 2003). Os parâmetros são a distância focal da câmera, as coordenadas das marcas fiduciais em pixel e os parâmetros de distorção do sistema de lentes. Os parâmetros de orientação exterior são os elementos que definem a posição (coordenadas X, Y e Z) e a orientação (ângulos de Euler w, f, K) da câmera segundo um referencial terrestre. Tratando-se de RPA, essas informações são obtidas preliminarmente pelos sensores embarcados na aeronave: receptor GNSS, acelerômetro, giroscópio e barômetro, e podem ser armazenadas nos metadados (EXIF) das imagens para posterior leitura por softwares.

A ortorretificação transforma a visada cônica do sensor em imagens com perspectiva ortogonal e escala uniforme, corrigida do deslocamento devido ao relevo e à inclinação da câmera (Brito \& Coelho Filho, 2007, p. 169).São obtidos através de procedimentos de pré-calibração realizados em campo ou em laboratório (Andrade, 2003) ou através de algoritmos de visão computacional de forma automática.

Essa última forma, amplamente utilizada na fotogrametria digital e conhecido como autocalibração, consiste em rotinas computacionais para orientar cada imagem em relação à câmera. Atualmente existem diversos algoritmos que conseguem fazer esse trabalho, a exemplo do Structure from Motion (SfM) (Miřijovský \& Jakub, 2015) e o Scale Invariant Feature Transform (SIFT) que estão implementados em pacotes de processamento fotogramétrico, cuja metodologia constitui-se em identifica pontos homólogos entre imagens 
vizinhas, possibilitando a construção de um conjunto de coordenadas 3D (Harwin \& Lucieer, 2012), conhecido como nuvem de pontos esparsos.

No entanto, para obter melhor resultados para os produtos fotogramétricos a serem gerados, quando se opta pela autocalibração da câmera, é recomendado que se use denso conjunto de pontos de controle e que se faça uso, também, de imagens oblíquas em complemento a imagens ortogonais. Adotando-se esses procedimentos os resultados podem ser melhores do que os que seriam obtidos com a pré-calibração (Harwin \& Lucieer, 2012; Osborn, 2015). Por outro lado, para a produção de dados espaciais usando técnicas de fotogrametria digital, os parâmetros de orientação exterior são essenciais, considerando a necessidade de que cada pixel seja ortoprojetado digitalmente, em ponto com coordenadas conhecidas e compatíveis com o sistema de coordenadas do modelo digital de elevação (MDE) usado na ortoprojeção (Andrade, 2003).

Para tanto, mesmo no caso de RPA onde o posicionamento e atitude da câmera em relação a um referencial terrestre podem fazer parte dos metadados dos arquivos de imagem, para aprimorar as informações relativas aos parâmetros de orientação exterior, no que diz respeito a um modelo de representação da Terra, podem ser utilizados pontos de apoio localizados na superfície do terreno, cujas coordenadas devem ser conhecidas. Tal procedimento, segundo Goldstein et al. (2015), produz modelos digitais de superfície com excelente acurácia.

Frisa-se que os pontos de apoio devem ser fotoidentificáveis, ou seja, visíveis nas fotografias aéreas, e podem ser utilizados para avaliação da qualidade posicional dos modelos digitais resultantes do processamento fotogramétrico, sendo fundamental não só a sua quantidade, mas também a distribuição apropriada desses pontos na área de interesse (Andrade, 2003).

Por conseguinte, é possível obter modelos matemáticos de representação da superfície terrestre, cujas características e acurácia permitem o uso para diversas finalidades, a exemplo de modelo digital de superfície (MDS), modelo digital de terreno (MDT) e mosaico de ortofoto.

Tanto o MDS quanto o MDT são representações da superfície da Terra, sendo que o primeiro representa a superfície considerando um atributo específico que pode ser temperatura, pressão, inclinação etc. (Brito \& Coelho Filho, 2007). O segundo, espécie do primeiro cujo atributo é a altura, representa a morfologia do terreno de forma contínua sem contemplar a vegetação e feições resultantes da ação antrópica, por ventura existentes na área de mapeada, e que não interessem ao levantamento que se pretende realizar.

Por seu turno, o mosaico de ortofoto, também conhecido como ortomosaico, é o resultado da união digital de ortofotos, que são imagens que foram ortorretificadas, ou seja, retificadas e tiveram os pixels ortoprojetados em um plano, a partir de informações de altura obtidas em um modelo numérico de elevação (MNE) (Andrade, 2003; Brito \& Coelho Filho, 2007).

Por conta disso, os ortomosaicos herdam das ortofotos suas características, no que se refere à ortogonalidade da projeção e à escala uniforme, o que os torna semelhantes a cartas topográficas, permitindo que sejam mensurados distâncias, ângulos e áreas.

Devido a essas características, os mosaicos de ortofotos permitem a restituição de feições planimétricas e, portanto, a elaboração de mapas temáticos ou plantas de situação com precisão centimétrica, rapidez e a baixo custo. $\mathrm{Na}$ atualidade, com a fotogrametria digital, é possível realizar digitalmente esse trabalho através de plataformas de desenho assistido por computador (CAD).

\section{MATERIAIS E METODOLOGIA}

Para a execução dos levantamentos de campo, foram utilizados trena eletrônica com feixe laser, pontos de apoio confeccionados em madeira compensada ou pintado diretamente na superfície, receptor GNSS geodésico, tablet para pilotagem e uma RPA modelo Phantom 4 Pro, fabricada pela DJI, equipada com câmera de 20 Mpixel, modelo FC6310.

As imagens capturadas foram processadas em um microcomputador, utilizando software de processamento fotogramétrico, para realizar a construção de modelos matemáticos de representação da área sobrevoada.

A metodologia empregada envolveu a escolha e o estudo prévio da área de pesquisa escolhida, seguida do levantamento fotogramétrico e do processamento de imagens e vetorização. $\mathrm{O}$ diagrama na figura 1 representa as etapas da 
metodologia adotada.

\section{Escolha da área de estudo}

O Riacho Cavouco é um afluente do Rio Capibaribe, tendo sua nascente na Universidade Federal de Pernambuco (UFPE), Com 5,5km de extensão (CABRAL et al., 2015), parte do riacho situada dentro da Universidade, no bairro da
Cidade Universitária, foi a área escolhida para realizar o aerolevantamento, tendo e vista tratarse de local de estudos e, por conseguinte, com informações precisas da superfície do terreno levantadas tanto com receptor GNSS quanto com estação total. A figura 2 mostra o mapa de localização da área de estudo.

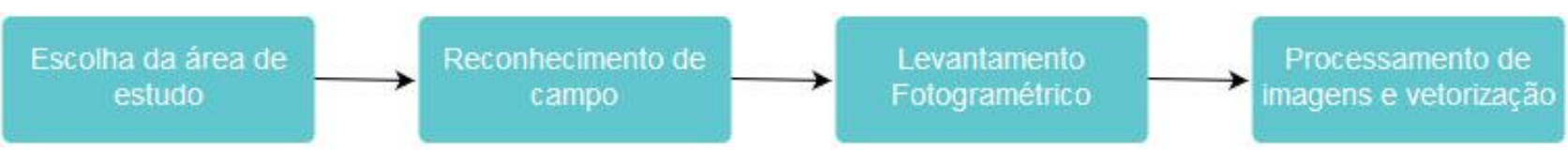

Figura 1 - Fluxo de trabalho.
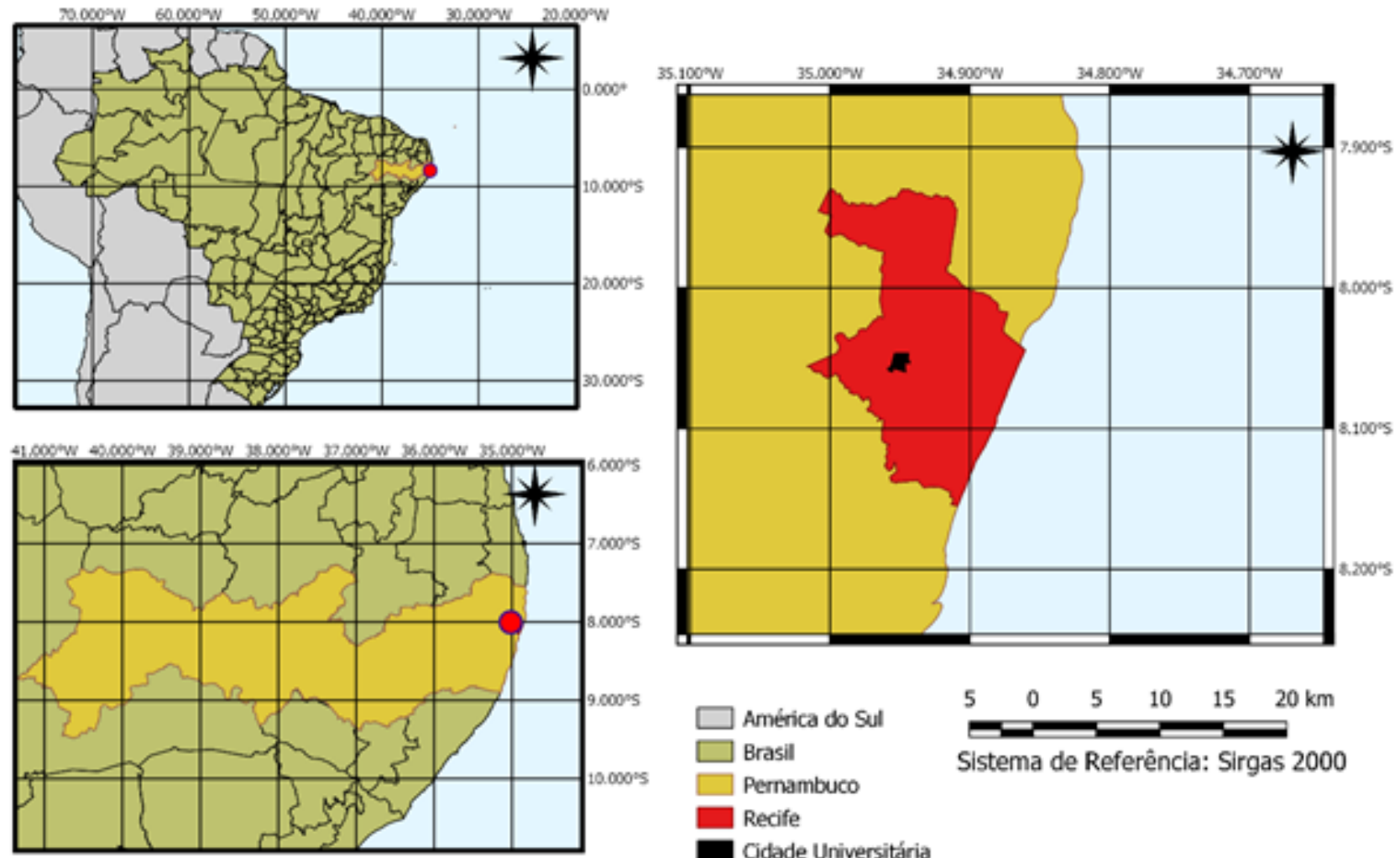

Figura 2 - Mapa de localização da área de estudo.

\section{Reconhecimento de campo}

Um estudo preliminar foi realizado para verificar a viabilidade do levantamento fotogramétrico. Antecedendo os trabalhos concretos de campo, foram colhidas informações atualizadas do local, que incluíram imagens orbitais fornecidas pelo software Google Earth. A partir destas imagens, foram estipuladas possíveis localizações de pontos de apoio a serem distribuídos em campo, levando em consideração a ausência de obstáculos físicos como edifícios e vegetação, que diminuem ou impossibilitam a captura de imagens desses pontos.

Em seguida, deu-se início a confecção do plano de voo, que definiu o percurso que a RPA iria percorrer, de forma automática, utilizando um aplicativo. O voo de mapeamento foi realizado a uma altura de $60 \mathrm{~m}$, com a câmera programada para conseguir imagens de $4.864 \mathrm{x}$ 3.648 pixels $(4 \times 3)$.

Deste modo, em tese, levando-se em conta que o conjunto de lentes da câmera tem distância focal de $8,8 \mathrm{~mm}$ e seu sensor eletrônico de captura de imagens tem 12,69154 mm de largura para imagens $4 \times 3$, essa configuração resultaria em fotografias com altura e largura de $64,90 \mathrm{x}$ $86,53 \mathrm{~m}$ e resolução espacial de $1,7 \mathrm{~cm}$, proporcionando uma excelente riqueza de detalhes.

O plano de voo foi configurado para ter dois momentos distintos de captura de imagens, o primeiro consistiu no mapeamento da área, 
realizando faixas paralelas de voo em visada ortogonal à superfície da térrea, sendo o cobrimento frontal de $70 \%$ entre as imagens e de $70 \%$ lateral entre as faixas de voo. Ainda no mesmo plano de voo, programou-se o segundo modo de captura de imagens, com o objetivo de que a aeronave retornasse ao ponto "start" e percorresse o perímetro da área de interesse com a câmera voltada para o interior, inclinada próximo a $45^{\circ}$, o que resultaria em 187 imagens e tempo estimado de voo de 10 minutos, consumindo menos de uma bateria da RPA.

\section{Levantamento Fotogramétrico}

O horário mais indicado para realizar levantamentos aerofotogramétricos compreendese entre as $10 \mathrm{~h}$ e as $14 \mathrm{~h}$, devido ser esse o horário o de melhor iluminação e menor quantidade de sobras, proporcionando os melhores resultados, em tese. Assim, o levantamento iniciou-se com alocação de pontos de controle e verificação para posterior aquisição de coordenadas utilizando um coletor de dados equipado com receptor GNSS do tipo RTK (Real Time Kinematic ou Posicionamento Cinemático em Tempo-Real), como base foi utilizado um dos marcos geodésico do campus Joaquim Amazonas da UFPE, localizado nas coordenadas $\mathrm{N}=9109407,837 \mathrm{~m}$, $\mathrm{E}=284650,091 \mathrm{~m}$, para o datum SIRGAS2000.

Para materializar os postos de apoio, foram confeccionados alvos em madeira compensada medidos $50 \times 50 \mathrm{~cm}$, para serem distribuídos nos locais com vegetação cobrindo o solo e, para nos pontos com grande fluxo de pessoas, foram pintados alvos com tinta branca em caçadas e passagens de concreto. A distribuição dos pontos de apoio é mostrada na figura 3.

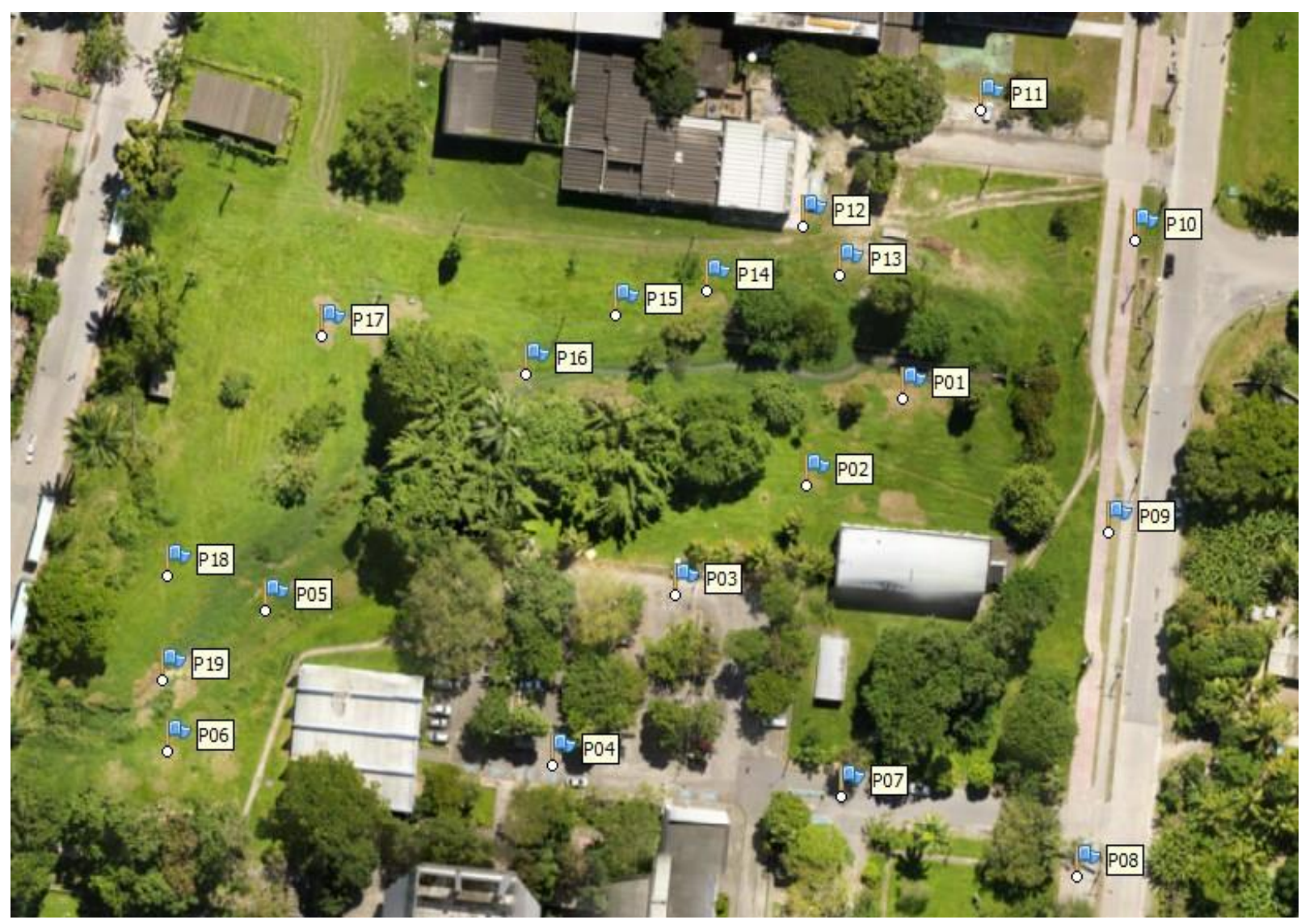

Figura 3 - Distribuição de pontos de apoio.

Após o levantamento de campo, a partir das coordenadas levantadas a ondulação geoidal foi calculada usando o aplicativo MAPGE0 2015, disponível no portal do IBGE, o que possibilitou encontrar a altitude ortométricas, cujos resultados são apresentados na figura 4 .

\section{Processamento de imagens}

Após a verificação da qualidade do imageamento, as 190 imagens obtidas foram carregadas no Agisoft PhotoScan, e foi realizado o primeiro alinhamento de fotos, a fim de gerar nuvem esparsa de pontos e estabelecer os parâmetros orientação interior da câmera. Tal procedimento resultou, consequentemente, na autocalibração da câmera, assim como uma nuvem esparsa de pontos homólogos identificados digitalmente pelo software. 


\begin{tabular}{|r|c|r|r|r|r|}
\hline Ponto & Leste & Norte & $\begin{array}{c}\text { Altitude } \\
\text { Elipsoidal }\end{array}$ & $\begin{array}{c}\text { Ondulação } \\
\text { Geoidal }\end{array}$ & $\begin{array}{c}\text { Altitude } \\
\text { Ortométrica }\end{array}$ \\
\hline P01 & $284.677,340$ & $9.109 .426,116$ & 2,207 & $-5,53$ & 7,737 \\
\hline P02 & $284.657,909$ & $9.109 .409,774$ & 3,942 & $-5,53$ & 9,472 \\
\hline P03 & $284.631,950$ & $9.109 .388,963$ & 4,556 & $-5,53$ & 10,086 \\
\hline P04 & $284.607,656$ & $9.109 .356,681$ & 5,085 & $-5,53$ & 10,615 \\
\hline P05 & $284.550,480$ & $9.109 .385,845$ & 3,261 & $-5,53$ & 8,791 \\
\hline P06 & $284.531,074$ & $9.109 .359,366$ & 3,941 & $-5,53$ & 9,471 \\
\hline P07 & $284.665,140$ & $9.109 .350,697$ & 5,202 & $-5,53$ & 10,732 \\
\hline P08 & $284.711,818$ & $9.109 .335,495$ & 5,011 & $-5,53$ & 10,541 \\
\hline P09 & $284.718,177$ & $9.109 .400,785$ & 5,107 & $-5,53$ & 10,637 \\
\hline P10 & $284.723,391$ & $9.109 .456,312$ & 5,051 & $-5,53$ & 10,581 \\
\hline P11 & $284.692,590$ & $9.109 .481,004$ & 4,759 & $-5,53$ & 10,289 \\
\hline P12 & $284.657,551$ & $9.109 .458,823$ & 4,74 & $-5,53$ & 10,27 \\
\hline P13 & $284.664,794$ & $9.109 .449,700$ & 4,474 & $-5,53$ & 10,004 \\
\hline P14 & $284.638,353$ & $9.109 .446,472$ & 3,02 & $-5,53$ & 8,55 \\
\hline P15 & $284.620,275$ & $9.109 .441,873$ & 2,663 & $-5,53$ & 8,193 \\
\hline P16 & $284.602,293$ & $9.109 .430,701$ & 1,569 & $-5,53$ & 7,099 \\
\hline P17 & $284.561,735$ & $9.109 .438,161$ & 3,082 & $-5,53$ & 8,612 \\
\hline P18 & $284.531,009$ & $9.109 .392,640$ & 3,118 & $-5,53$ & 8,648 \\
\hline P19 & $284.530,039$ & $9.109 .372,740$ & 1,901 & $-5,53$ & 7,431 \\
\hline
\end{tabular}

Figura 4 - Pontos de apoio.

Após esse primeiro processamento, os pontos de apoio foram inseridos e associados as imagens que apareciam. Definido os pontos que seriam usados como pontos de controle e os que serviriam como ponto de checagem, novo processamento foi realizado e o Erro Médio Quadrático Planimétrico $\left(\mathrm{EMQ}_{\mathrm{H}}\right)$ e o Erro Médio Quadrático Altimétrico (EMQz) foram calculados, a partir das especificações da norma EB80-N-72.004 (BRASIL, 2016).

Os resultados obtidos para o $\mathrm{EMQ}_{\mathrm{H}}(2,72$ $\mathrm{cm})$ e o EMQz $(3,24 \mathrm{~cm})$ para os pontos de checagem revelaram acurácia do modelo gerado atendia a EB80-N-72.003 para classe A, escala 1:000, tendo em vista que essa classe exige que o produto digital tenha $90 \%$ dos pontos testados com erros inferior a $27 \mathrm{~cm} \mathrm{e}$ EMQ inferior a $17 \mathrm{~cm}$.

$\mathrm{Na}$ figura 5 são apresentados os resultados encontrados para os erros calculados, tanto planimétrico quanto altimétrico, além do erro total (XYZ), e na figura 6, são ilustrados os resultados encontrados para os pontos de controle.

\begin{tabular}{|c|c|c|c|c|c|c|c|c|c|c|c|}
\hline \multirow[b]{2}{*}{ Ponto } & \multicolumn{3}{|c|}{ Coordenadas GNSS } & \multicolumn{3}{|c|}{ Coordenadas Calculadas } & \multicolumn{5}{|c|}{ Erro $(\mathrm{cm})$} \\
\hline & $\mathrm{x}$ & \begin{tabular}{|r|} 
\\
\end{tabular} & $z$ & \begin{tabular}{l|l}
$x$ & \\
\end{tabular} & $\mathrm{Y}$ & $z$ & $\mathrm{x}$ & $\mathrm{Y}$ & 2 & $X Y$ & $X Y Z$ \\
\hline P03 & 284631,950 & 9109388,963 & 10,086 & 284631,956 & 9109388,996 & 10,088 & 0,0062 & 0,0333 & 0,0025 & 0,0338 & 0,0339 \\
\hline P04 & 284607,656 & 9109356,681 & 10,615 & 284607,667 & 9109356,686 & 10,553 & 0,0113 & 0,0047 & $-0,0624$ & 0,0122 & 0,0635 \\
\hline P05 & 284550,480 & 9109385,845 & 8,791 & 284550,508 & 9109385,842 & 8,813 & 0,0284 & $-0,0034$ & 0,0223 & 0,0286 & 0,0363 \\
\hline P09 & 284718,177 & 9109400,785 & 10,637 & 284718,154 & 9109400,801 & 10,652 & $-0,0225$ & 0,0158 & 0,0149 & 0,0275 & 0,0313 \\
\hline P13 & 284664,794 & 9109449,700 & 10,004 & 284664,817 & 9109449,712 & 10,031 & 0,0231 & 0,0119 & 0,0275 & 0,0260 & 0,0378 \\
\hline P16 & 284602,293 & 9109430,701 & 7,099 & 284602,256 & 9109430,702 & 7,074 & $-0,0367$ & 0,0014 & $-0,0251$ & 0,0367 & 0,0445 \\
\hline P18 & 284531,009 & 9109392,640 & 8,648 & $284531,021$. & 9109392,653 & 8,685 & 0,0123 & 0,0128 & 0,0369 & 0,0177 & 0,0410 \\
\hline & & & & & & Total & 2,2401 & 1,5572 & 3,2434 & 2,7282 & 4,2382 \\
\hline
\end{tabular}

Figura 5 - Erros Médios Quadráticos encontrados para os pontos de checagem.

Verificada a acurácia do modelo e também confirmado que todas imagens estavam com qualidade e inclinação adequadas ao processamento, o tratamento fotogramétrico poderia prosseguir, a fim de que fossem gerados outros produtos digitais.

Em seguida, foi feita a densificação da nuvem de pontos e para aquisição de um modelo numérica que representasse a superfície do terreno, essa nuvem foi classificada automaticamente, de forma 
a dar classe distinta à do terreno às edificações, à como terreno, resultando na imagem apresentada vegetação a aos objetos que estavam sendo tratados na figura 7 .

\begin{tabular}{|c|c|c|c|c|c|c|c|c|c|c|c|}
\hline \multirow[b]{2}{*}{ Ponto } & \multicolumn{3}{|c|}{ Coordenadas GNSS } & \multicolumn{3}{|c|}{ Coordenadas Calculadas } & \multicolumn{5}{|c|}{ Erro $(\mathrm{cm})$} \\
\hline & $\mathrm{x}$ & Y & $z$ & $x$ & Y & $z$ & $\mathrm{x}$ & Y & $z$ & $X Y$ & $X Y Z$ \\
\hline P01 & 284677,34 & 9109426,116 & 7,737 & $284.677,354$ & $9.109 .426,085$ & 7,757 & 0,0143 & $-0,0306$ & 0,0198 & 0,0338 & 0,0392 \\
\hline P02 & 284657,909 & 9109409,774 & 9,472 & $284.657,936$ & $9.109 .409,785$ & 9,481 & 0,0266 & 0,0110 & 0,0092 & 0,0288 & 0,0302 \\
\hline P06 & 284531,074 & 9109359,366 & 9,471 & $284.531,068$ & $9.109 .359,325$ & 9,412 & $-0,0063$ & $-0,0407$ & $-0,0586$ & 0,0411 & 0,0716 \\
\hline P07 & 284665,14 & 9109350,697 & 10,732 & $284.665,125$ & $9.109 .350,729$ & 10,742 & $-0,0148$ & 0,0320 & 0,0095 & 0,0353 & 0,0366 \\
\hline P08 & 284711,818 & 9109335,495 & 10,541 & $284.711,792$ & $9.109 .335,479$ & 10,543 & $-0,0259$ & $-0,0160$ & 0,0018 & 0,0304 & 0,0305 \\
\hline P10 & 284723,391 & 9109456,312 & 10,581 & $284.723,393$ & $9.109 .456,305$ & 10,544 & 0,0015 & $-0,0067$ & $-0,0369$ & 0,0069 & 0,0375 \\
\hline P11 & 284692,59 & 9109481,004 & 10,289 & $284.692,588$ & $9.109 .481,018$ & 10,281 & $-0,0025$ & 0,0142 & $-0,0081$ & 0,0144 & 0,0165 \\
\hline P12 & 284657,551 & 9109458,823 & 10,27 & $284.657,544$ & $9.109 .458,836$ & 10,276 & $-0,0070$ & 0,0134 & 0,0060 & 0,0151 & 0,0162 \\
\hline P14 & 284638,353 & 9109446,472 & 8,55 & $284.638,359$ & $9.109 .446,491$ & 8,559 & 0,0062 & 0,0190 & 0,0091 & 0,0200 & 0,0219 \\
\hline P15 & 284620,275 & 9109441,873 & 8,193 & $284.620,266$ & $9.109 .441,865$ & 8,203 & $-0,0094$ & $-0,0080$ & 0,0104 & 0,0123 & 0,0161 \\
\hline P17 & 284561,735 & 9109438,161 & 8,612 & $284.561,733$ & $9.109 .438,168$ & 8,617 & $-0,0020$ & 0,0070 & 0,0054 & 0,0073 & 0,0091 \\
\hline P19 & 284530,039 & 9109372,74 & 7,431 & $284.530,057$ & $9.109 .372,748$ & 7,465 & 0,0179 & 0,0083 & 0,0340 & 0,0197 & 0,0393 \\
\hline & & & & & & Total & 1,3989 & 2,0331 & 2,3891 & 2,4679 & 3,4349 \\
\hline
\end{tabular}

Figura 6 - Erros Médios Quadrados encontrados para os pontos de controle.

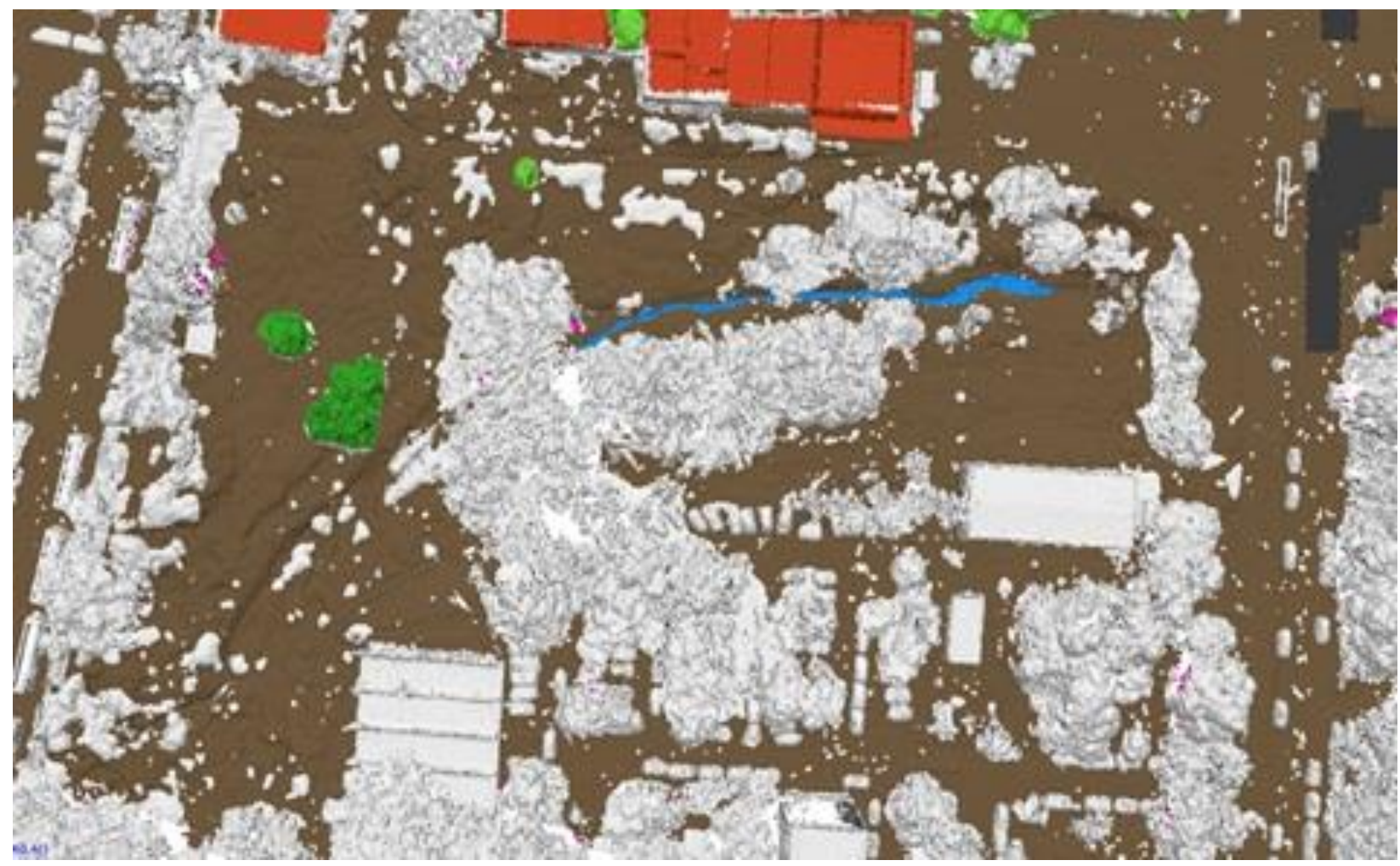

Figura 7 - Ilustração da classificação realizada na nuvem de pontos.

\section{RESULTADOS E CONSIDERAÇÕES}

O modelo tridimensional da área sobrevoada, obtido a partir da nuvem de pontos densa, possibilitou a confecção do modelo digital de superfície mostrado na figura 8 , representado através de variação de tonalidade, sendo que o azul corresponde a menor cota e o vermelho a maior cota, o qual permite distinguir inclusive pequenas elevações a exemplo de rampas e calçadas, em decorrência do GSD de 4,07 cm obtido para o modelo.
O modelo digital do terreno (MDT), gerado apenas com pontos da nuvem densa classificados como terreno, proporcionou a representação da variação de elevação do terreno, em volta do riacho cavouco. A figura 9 apresenta o MDT obtido, associado a curvas de nível com espaçamento de $.25 \mathrm{~cm}$.

Outro produto fotogramétrico gerado, foi o mosaico de ortofotos da área (Figura 10), cuja resolução espacial resultou em GSD de 1,6 cm. 


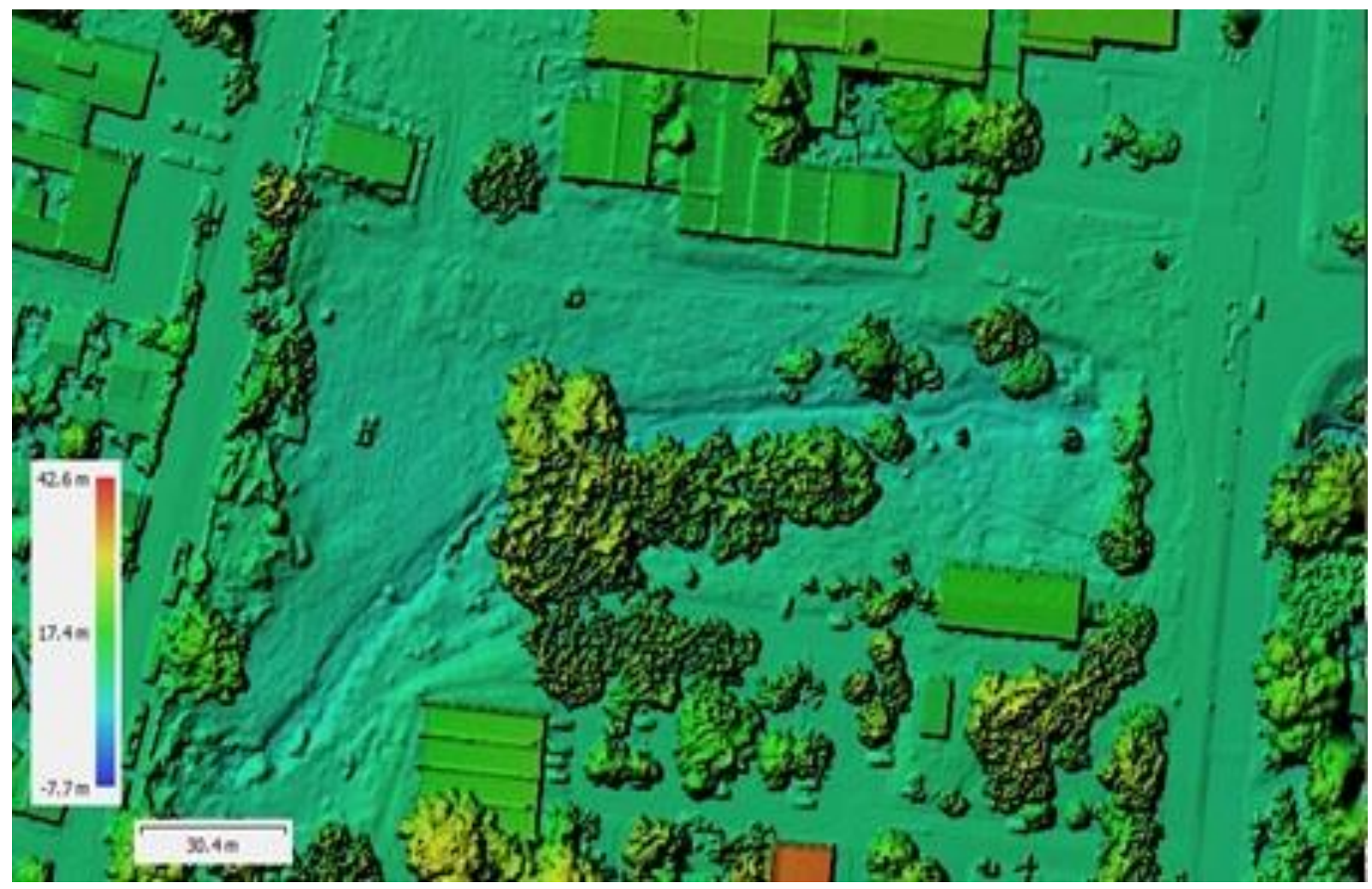

Figura 8 - Modelo digital da superfície obtido a partir da nuvem de pontos.

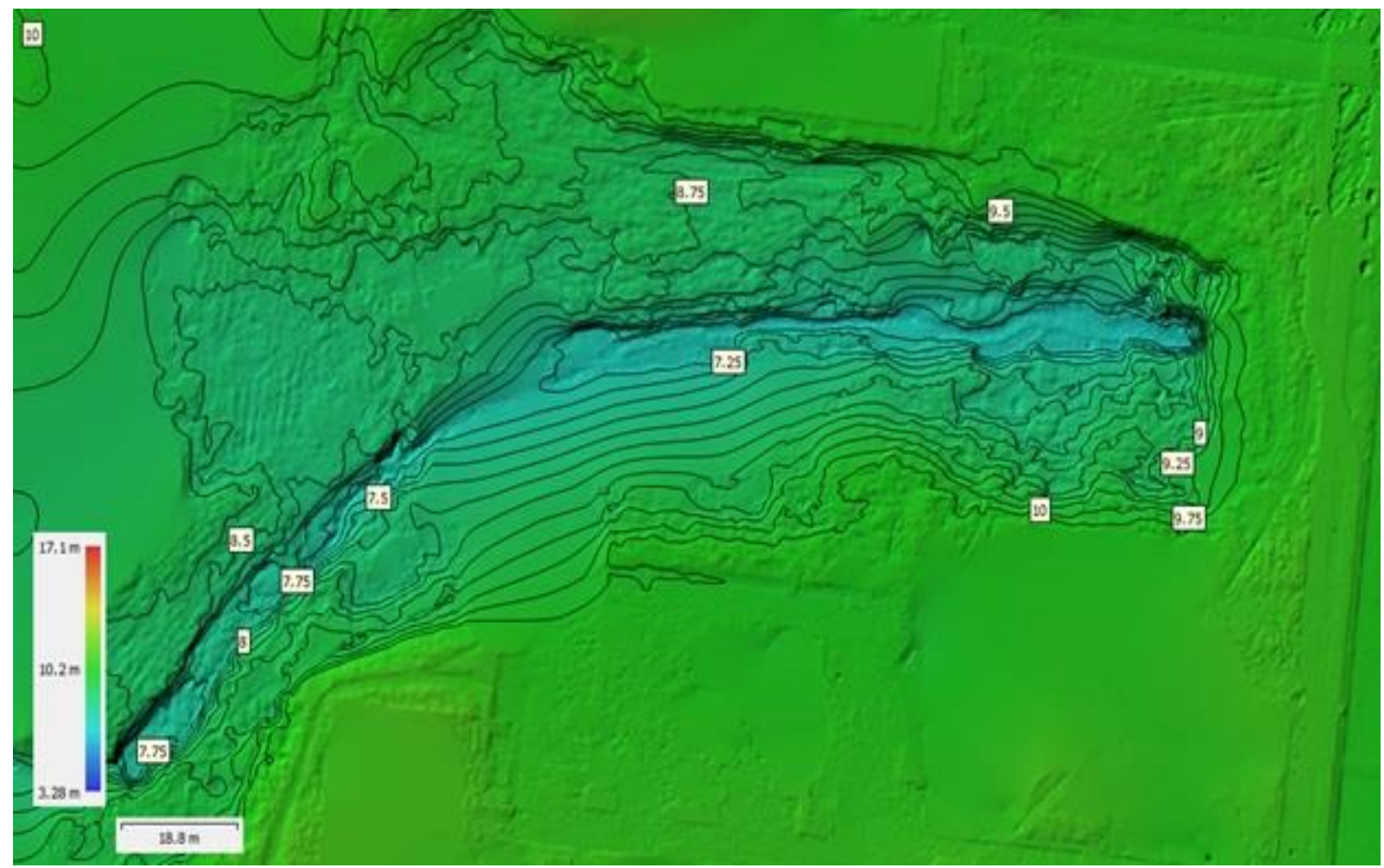

Figura 9 - Modelo digital do terreno.

Este mosaico possibilitou a geração de GSD, Ground Sample Distance, de 1,6 cm imagem raster, utilizável em sistemas de permitiu a vetorização de feições presente na área informações geográficas e aplicativos de desenho mapeada, possibilitando a confecção de plantas assistidos por computador (CAD), assim como de situação e mapas temáticos, com nível de arquivo de extensão “. $K M Z$ ” compatível com detalhamento que pode comtemplar meio-fio, Google Earth.

Analisando o ortomosaico obtido, verificouse que ele possui excelente definição e que o calçadas e caixas de passagem, como é possível observar na figura 11, alcançada a partir de um recorte ampliado do ortomosaico. 


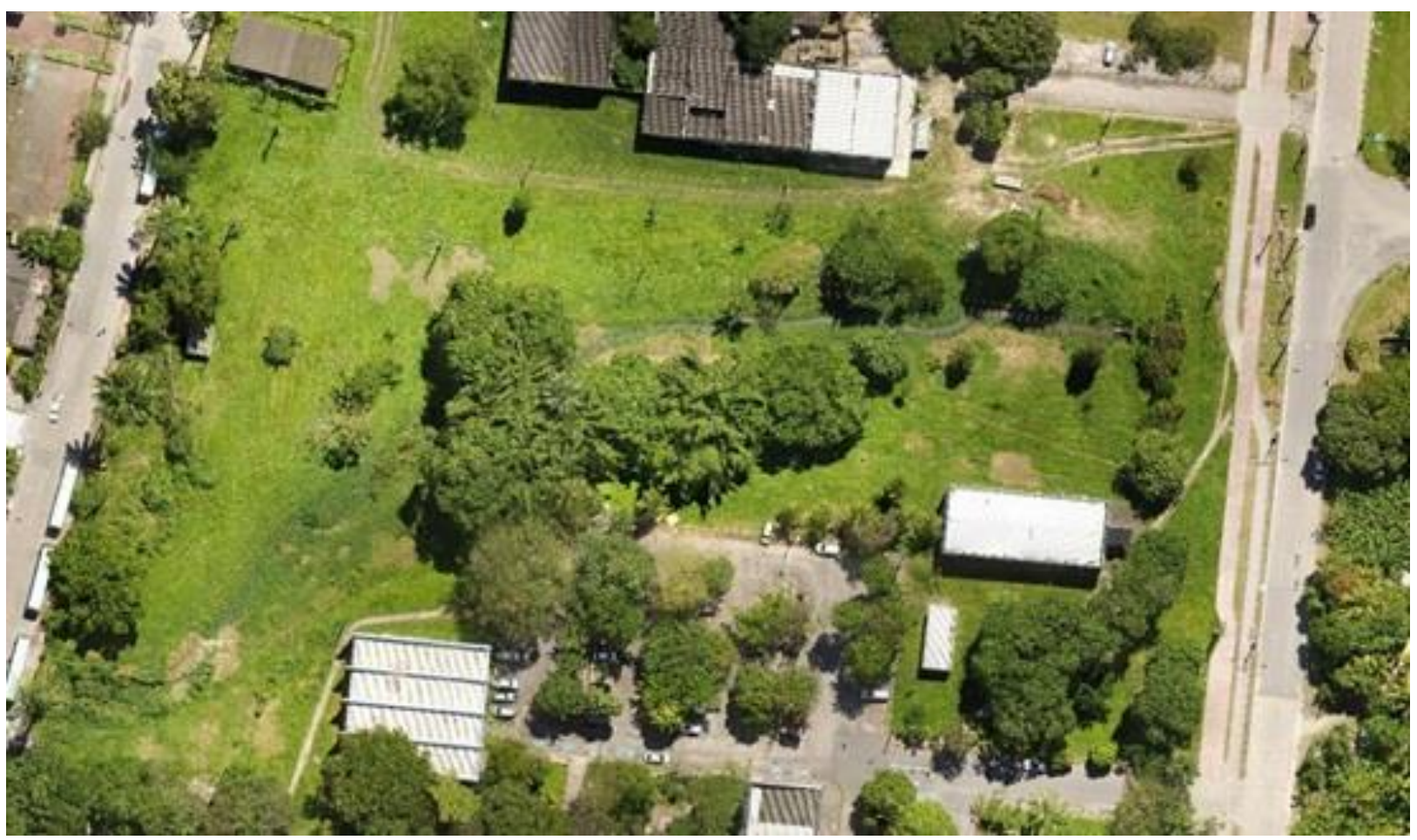

Figura 10 - Ortomosaico elaborado para a área.

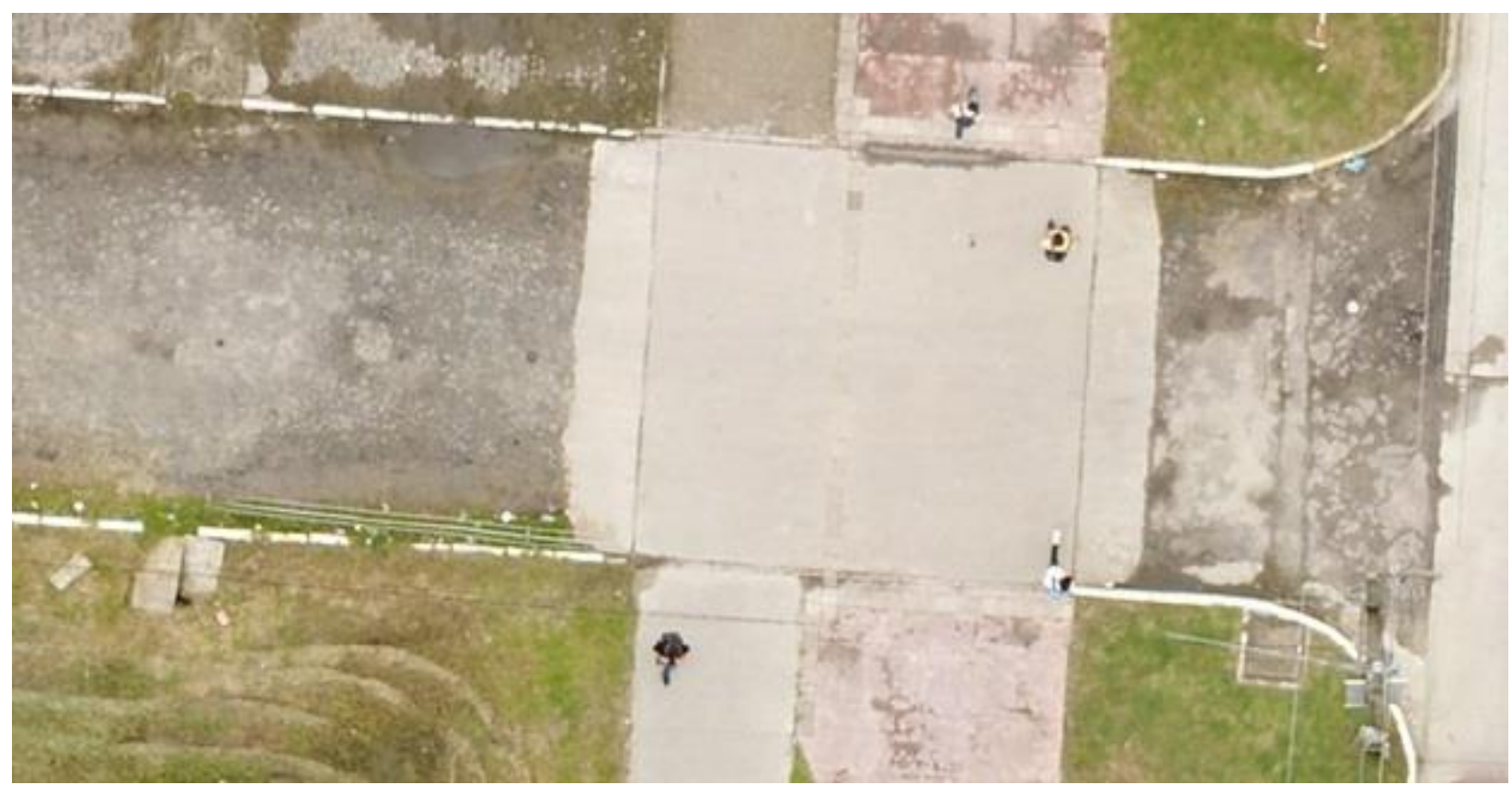

Figura 11 - Detalhe do ortomosaico gerado.

Do ponto de vista da acurácia dos produtos tendo em vista que essa classe exige que o produzidos, verificou-se que o EMQ $_{\mathrm{H}}(2,72$ produto digital tenha $90 \%$ dos pontos testados $\mathrm{cm})$ e o $\mathrm{EMQ}_{z}(3,24 \mathrm{~cm})$ atendem a Classe A, com erros inferior a $27 \mathrm{~cm}$ e EMQ inferior a para escala 1:000, da norma EB80-N-72.003, $17 \mathrm{~cm}$.

\section{CONCLUSÃO}

A acessibilidade referente ao desenvolvimento da tecnologia, que permitiu evoluir os meios de aquisição e processamento de dados espaciais tem expandido o potencial de mapeamento de áreas que antes dependiam de equipamentos mais robustos, caros, e por vezes, com pouca acurácia.

O surgimento da PEC, o Padrão de Exatidão Cartográfica, ajudou a tornar a produção cartográfica no Brasil mais homogeneizada, estipulando um controle de qualidade. Com o crescimento da utilização de RPAs no país e a criação em progresso de uma regulamentação, houve um questionamento sobre a acurácia 
possibilitada por esta tecnologia.

Neste estudo, verificou-se a possibilidade de diversificação de produção fotogramétrica, a exemplo do mosaico de ortofotos e do modelo digital do terreno, e quanto a acurácia dos produtos cartográficos, percebeu-se que o $\mathrm{EMQ}_{\mathrm{H}}$ e o EMQz atendem a Classe A, constituindo alto padrão de qualidade.

\section{REFERÊNCIAS}

AGISOFT LLC. Agisoft PhotoScan User Manual: Professional Edition, Version 1.4, 2017. Agisoft LLC. St. Petersburg, Rússia, 2017. Disponível em: www.agisoft.com. Acesso em 18Jun2018.

ANDRADE, J.B. Fotogrametria. Curitiba: SBEE, 274 p., 2003. BENNETT, R.; GERKE, M.; STÖCKER, C.; NEX, F., ZEVENBERGEN, J. Review of the current state of UAV regulations, Remote Sens. 9, 2017.

BRASIL, ANAC - AGÊNCIA NACIONAL DE AVIAÇÃO CIVIL. RBAC-E $\mathbf{n}^{\circ}$ 94: Requisitos gerais para aeronaves não tripuladas de uso civil. Brasília, 2017.

BRASIL, COMANDO DA AERONÁUTICA, MINISTÉRIO DA DEFESA. AIC 24/18: Aeronaves remotamente pilotadas para uso exclusivo em operações dos órgãos de segurança pública, da defesa civil e de fiscalização da receita federal. Rio de Janeiro, 2018.

BRASIL, COMANDO DA AERONÁUTICA, MINISTÉRIO DA DEFESA. ICA 100-40: Sistemas de aeronaves remotamente pilotadas e o acesso ao espaço aéreo brasileiro. Rio de Janeiro, 2017.

BRASIL, DIRETORIA DO SERVIÇO GEOGRÁFICO DSG. EB80-N-72.004: Especificação técnica para a aquisição de dados geoespaciais vetoriais. Brasília, 2016

BRASIL, Palácio do Planalto: Decreto $\mathbf{N}^{\circ} \mathbf{8 9 . 8 1 7}, 1984$.

BRITO, J.L.N.S \& COELHO FILHO, L.C.T. Fotogrametria digital - Rio de Janeiro: Editora UERJ, 2007. 196 p.

CABRAL, J.J.S.P; CERQUINHA, G; GUSMÃO, M.B.R. \& CARVALHO, A.F. Início da mudança de paradigma em relação aos cuidados com rios e riachos urbanos em Recife. SIMPÓSIO BRASILEIRO DE RECURSOS HÍDRICOS, XXI, Brasília, 2015. Anais...Brasilia.

CHODORONEK, M. The use and application of photogrammetry for in-field documentation for archaeological features: Three case studies from the great plains and southeastern Alaska. Dissertação (Mestrado), Universidade de Nebraska-Linconl, 2015.

EXÉRCITO DO BRASIL. INFRAESTRUTURA NACIONAL DE DADOS ESPACIAIS Especificação Técnica para a Aquisição de Dados Geoespaciais Vetoriais (ET-ADGV). Editoração e impressão pela Diretoria de Serviço Geográfico do Exército Brasileiro, 2a Edição, 2011

GOLDSTEIN, E.B.; OLIVER, A.R.; DE VRIES, E.; MOORE, L.J.; JASS, T. Ground control point requirements for structurefrom-motion derived topography in lowslope coastal environments. PeerJ PrePrints, v. 3, 2015.
HARWIN, A.S. \& LUCIEER, J. Assessing the accuracy of georeferenced point clouds produced via multi-view stereopsis from unmanned aerial vehicle (UAV) imagery, Remote Sensing, v. 4, p. 1573-1599, 2012.

HARWIN, A.S. \& LUCIEER, J. Osborn, The impact of the calibration method on the accuracy of point clouds derived using unmanned aerial vehicle multi-view stereopsis, Remote Sensing, p. 11933-11953, 2015.

KANGAS, A.; GOBAKKEN, T.; PULITI, S.; HAUGLIN, M.; $\mathrm{N} Æ S S E T, E$. Value of airborne laser scanning and digital aerial photogrammetry data in forest decision making. Silva Fennica, v. 52 n. 1.19 p, 2018.

LEVUSH, R. Regulation of drones. The Law Library of Congress: 2016

PILLAY, S. Aerial Photogammetry. Surveying and land information department. Ethekwini, 2015.

PILLAY, S. Aerial Photogammetry. Surveying and land information department. Surverying and land information department, Ethekwini, 2015.

REZENDE, W.S. Do analógico ao digital: a evolução das técnicas de documentação do ambiente construído. Jundiaí/SP: Paco Editorial. $1^{a}$ Ed., 176 p., 2016.

SKARLATOS, D.; PROCOPIOUB, G.; STAVROUC, G.; GREGORIOUA, M. Accuracy assessment of minimum control points for UAV photography and georeferencing. The international Society of Optical Engineering, 2013.

UNHAMMER, O.F. Methodological evaluation of digital photogrammetry in a middle stone age cave context: A case of study from Blombos Cave, South Africa. Bergen, 2016. Dissertação (Mestrado) Universidade de Bergen.

YILMAZ, H.M; Yakar, M; YILDIZ, F. DIGITAL PHOTOGRAMMETRY IN OBTAINING OF 3D MODEL DATA OF IRREGULAR SMALL OBJECTS. The international archives of Photogrammetry, Remote Sensing and Spatial Information Sciences, v. 37, p. 125-130, 2008.

Submetido em 26 de novembro de 2018 Aceito para publicação em 18 de maio de 2020 